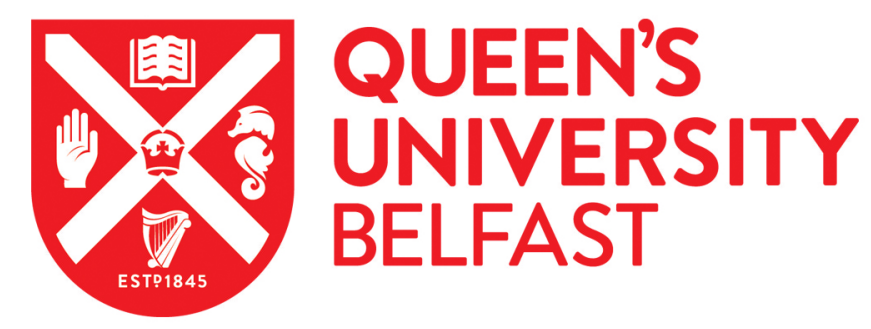

\title{
High energy resolution fluorescence detection XANES - an in situ method to study the interaction of adsorbed molecules with metal catalysts in the liquid phase
}

Manyar, H. G., Morgan, R., Morgan, K., Yang, B., Hu, P., Szlachetko, J., Sa, J., \& Hardacre, C. (2013). High energy resolution fluorescence detection XANES - an in situ method to study the interaction of adsorbed molecules with metal catalysts in the liquid phase. Catalysis, Science \& technology, 3(6), 1497-1500. https://doi.org/10.1039/c3cy00031a

\section{Published in:}

Catalysis, Science \& technology

Document Version:

Early version, also known as pre-print

Queen's University Belfast - Research Portal:

Link to publication record in Queen's University Belfast Research Portal

Publisher rights

Copyright 2013 The Author

\section{General rights}

Copyright for the publications made accessible via the Queen's University Belfast Research Portal is retained by the author(s) and / or other copyright owners and it is a condition of accessing these publications that users recognise and abide by the legal requirements associated with these rights.

Take down policy

The Research Portal is Queen's institutional repository that provides access to Queen's research output. Every effort has been made to ensure that content in the Research Portal does not infringe any person's rights, or applicable UK laws. If you discover content in the

Research Portal that you believe breaches copyright or violates any law, please contact openaccess@qub.ac.uk. 


\title{
High Energy Resolution Fluorescence Detection XANES - an in situ method to study the interaction of adsorbed molecules with metal catalysts in the liquid phase
}

\author{
Haresh G. Manyar, ${ }^{a}$ Richard Morgan, ${ }^{a}$ Kevin Morgan, ${ }^{a}$ Bo Yang, ${ }^{a}$ P. Hu, ${ }^{a}$ Jakub Szlachetko, ${ }^{b, c}$ Jacinto \\ 5 Sá, $^{b^{*}}$ Christopher Hardacre ${ }^{a^{*}}$
}

\author{
Received (in $X X X, X X X)$ Xth $X X X X X X X X X 20 X X$, Accepted Xth $X X X X X X X X X 20 X X$ \\ DOI: $10.1039 / b 000000 x$
}

The change in the Pt electronic structure following the adsorption of an $\boldsymbol{\alpha}, \boldsymbol{\beta}$-unsaturated aldehyde and ketone was

10 followed by in situ HERFD-XANES in the liquid phase. The resulting shift in the Pt Fermi energy is in good agreement with the molecule adsorption energy trends calculated by DFT and provides insight into the reaction selectivity.

In most heterogeneously catalysed chemical reactions in the fine,

15 pharmaceutical and petrochemical industries, the choice of the catalyst (active catalytic species and support) significantly modulates the reaction rate and product selectivity. This is due to their influence on the interaction of organic molecules with the catalytically active site. $\alpha, \beta$-Unsaturated aldehydes and ketones are

20 of particular interest due the complex reaction network resulting from the preferential adsorption geometry and strength of the interaction of different functional groups (often multiple aliphatic/aromatic $\mathrm{C}=\mathrm{C}$ or $\mathrm{C}=\mathrm{O}$ double bonds) on the active metal centre or support. This interaction is strongly influenced by the

25 metal electronic structure, for example, and thus it is an important parameter in determining the rate and product selectivity.

In gas phase heterogeneously catalysed reactions the reactant and product adsorption/desorption characteristics are routinely determined with the help of spectroscopic methods, for example in

30 situ diffuse reflectance infra-red spectroscopy. However, this is considerably more difficult to study in the liquid phase primarily due to the presence of the solvent. ${ }^{1}$ Furthermore, as many liquid phase heterogeneously catalysed reactions are performed in pressurized autoclaves, this provides an additional barrier to attain

35 information about molecular adsorption/desorption and how they are affected by the electronic structure of active site.

Within this paper, we report an in situ study on the interaction of molecules with a supported metal catalyst in a pressurized reactor by means of X-ray absorption spectroscopy (XAS). This

40 approach has been used in the past to determine the oxidation state of the active phase in liquid phase ${ }^{2}$ but to the best of our knowledge has never been used to evaluate the influence of adsorbed molecules on the electronic structure of the active site. This information has the potential to allow the determination of reactant

45 and product coverage under reaction conditions by a simple deconvolution of the individual spectral components if they are spectroscopically distinct.
In situ liquid phase X-ray absorption near edge spectroscopy (XANES) was performed in a homemade cell comprised of a 50 stainless steel autoclave reactor with window comprising of a polyether ether ketone (PEEK) insert. ${ }^{3}$ The Pt L III edge was monitored using High Energy Resolution Fluorescence Detection (HERFD) recently introduced to the SuperXAS beamline of the Swiss Light Source (SLS). ${ }^{4}$ This technique has been shown to be 55 very sensitive ${ }^{5}$ and able to discriminate adsorption of molecules in gas phase reactions. ${ }^{6}$ Ketoisophorone (KIP) and cinnamaldehyde $(\mathrm{CIN})$ were used as probe molecules. Selective hydrogenations of $\alpha, \beta$-unsaturated aldehydes and ketones are highly desirable reactions in the fine chemical industry, especially in the production 60 of flavours, fragrances and pharmaceuticals. ${ }^{7}$

We have shown recently that $5 \mathrm{wt} \% \mathrm{Pt} / \mathrm{OMS}-2$ (Pt (average particle diameter $2 \mathrm{~nm}$ ) supported on cryptomelane manganese oxide octahedral molecular sieve) provides high selectivity for the hydrogenation of both KIP and CIN (see ESI for reaction 65 conditions and schemes). ${ }^{8}$ In the case of KIP, 98\% selectivity for the selective reduction of the $\mathrm{C}=\mathrm{C}$ bond occurred resulting in the production of (6R)-2,2,6-trimethylcyclohexane-1,4-dione (levodione) at $100 \%$ conversion. OMS-2 was also found to be active for the same hydrogenation and also formed levodione

70 selectively (97\%), albeit at a lower reaction rate. In the case of $\mathrm{CIN}, 80 \%$ selectivity for the reduction of the $\mathrm{C}=\mathrm{O}$ bond forming cinnamyl alcohol at $100 \%$ conversion was found using $5 \mathrm{wt} \%$ $\mathrm{Pt} / \mathrm{OMS}-2$. In contrast, when OMS-2 was used in the absence of $\mathrm{Pt}, \mathrm{C}=\mathrm{C}$ bond hydrogenation dominated with $86 \%$ selectivity to 75 hydrocinnamaldehyde. The selectivity for the KIP is in contrast with the expected behaviour for Pt which commonly preferentially hydrogenates $\mathrm{C}=\mathrm{O}$ versus $\mathrm{C}=\mathrm{C}$ bond. The latter selectivity is observed when the reaction was performed over $5 \mathrm{wt} . \% \mathrm{Pt} / \mathrm{Al}_{2} \mathrm{O}_{3}$ under the same reaction conditions resulting in $91 \%$ selectivity 80 towards 4 -hydroxyisophorone at $70 \%$ conversion with only $5 \%$ selectivity to levodione. A possible explanation for the differences in the type of functional group being hydrogenated is that adsorption occurs on different sites on the catalyst.

To investigate this, Pt L LII-edge HERFD-XANES was measured 85 in the liquid phase experiments using $300 \mathrm{mg}$ of $5 \mathrm{wt} . \% \mathrm{Pt} / \mathrm{OMS}-$ 2 and $20 \mathrm{~cm}^{3}$ of solvent (10 mol.\% methanol in water) exposed to either $0.006 \mathrm{~mol}$ of KIP or CIN or $1 \mathrm{MPa} \mathrm{H}_{2}$ at $373 \mathrm{~K}$. Figure 1 shows the resulting HERFD-XANES data and the Fermi energy 
level shifts observed are summarized in Table 1.

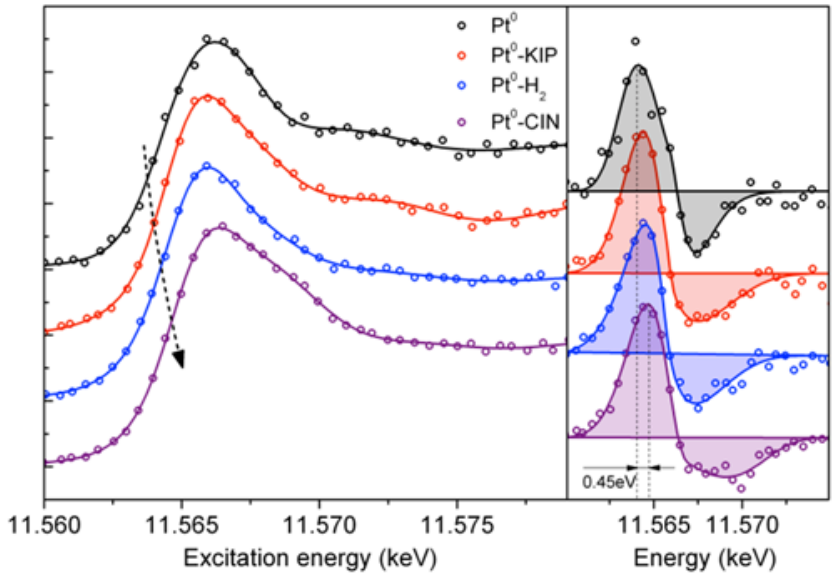

5 Figure 1. Pt $\mathrm{L}_{\mathrm{III}}$ edge HERFD-XANES spectra (left) and $1^{\text {st }}$ derivative (right) of Pt/OMS-2 interacting with $\mathrm{H}_{2}$, KIP and CIN. The spectra were recorded in situ in $10 \mathrm{~mol} \%$ methanol in water at $373 \mathrm{~K}$. The lines are from a least squares fitting procedure (see ESI for details).

10 Table 1: Shifts of Fermi energy level $\left(E_{f}\right)$ position estimated from the position of the $\mathrm{Pt} \mathrm{L}_{\text {III }}$ edge inflection point for $\mathrm{Pt} / \mathrm{OMS}-2$ before and after adsorption of CIN, KIP and $\mathrm{H}_{2}$ compared with $\mathrm{Pt}(\mathrm{acac})_{2}$ and $\mathrm{PtO}_{2}$. The errors are determined from the fitting procedure.

\begin{tabular}{lccc}
\hline Sample & $\begin{array}{c}\mathbf{E}_{\mathrm{f}} \text { shifts relative to } \\
\text { Pt/OMS-2 }(\mathbf{e V})\end{array}$ & $\begin{array}{c}\text { Error } \\
(\mathbf{e V})\end{array}$ & 50 \\
\hline $\mathrm{Pt} / \mathrm{OMS}-2$ & 0.00 & 0.13 \\
$\mathrm{Pt} / \mathrm{OMS}-2+\mathrm{KIP}$ & 0.19 & 0.09 \\
$\mathrm{Pt} / \mathrm{OMS}-2+\mathrm{H}_{2}$ & 0.28 & 0.08 & 5 \\
$\mathrm{Pt} / \mathrm{OMS}-2+\mathrm{CIN}$ & 0.45 & 0.09 & \\
$\mathrm{Pt}(\mathrm{acac})_{2}$ & 1.20 & 0.01 \\
$\mathrm{PtO}_{2}$ & 2.23 & 0.20 \\
\hline
\end{tabular}

The first important outcome of the experiments is that the addition of any molecule changes the position of the inflection point in the XAS spectra suggesting a significant coverage of the reactant molecule $(>10 \%)$. The second aspect is that all molecules

20 caused a shift of the Fermi energy level to higher energies, meaning that Pt electrons are, on average, donated to the adsorbed molecule with larger energy shifts indicating a stronger interaction, i.e. a higher adsorption energy. From the Fermi energy level shifts measured by Pt LIII-edge HERFD-XANES, it is expected that CIN

25 has the strongest interaction with $\mathrm{Pt}$ followed by $\mathrm{H}_{2}$ and then KIP.

The adsorption energies for KIP and CIN on $\operatorname{Pt}(111), \operatorname{Pt}(211)$ and OMS-2(001) surfaces were calculated using density functional theory (DFT) calculations and the results are represented in Figure 30

2. The adsorption energies are calculated using equation (1):

$$
E_{a d}=E_{\text {total }}-\left(E_{g}+E_{\text {slab }}\right)
$$

where $E_{a d}$ is the adsorption energy, $E_{\text {total }}$ is the energy of the system after adsorption, $E_{g}$ is the energy of the gas phase molecule and

$35 E_{\text {slab }}$ is the energy of the slab. It should be noted that the solvent effect is not included explicitly in this system. In our previous work $^{8}$ it has already been demonstrated that, the chemistry including the selectivity can be adequately using this approach.

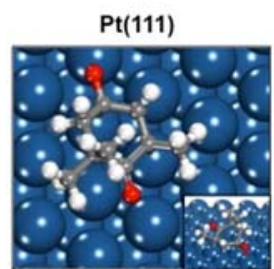

$$
E_{a d}=-0.32 \mathrm{eV}
$$

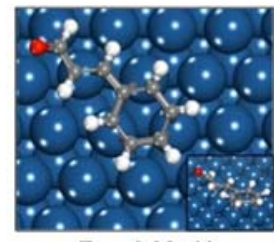

$E_{\mathrm{ad}}=-1.02 \mathrm{eV}$

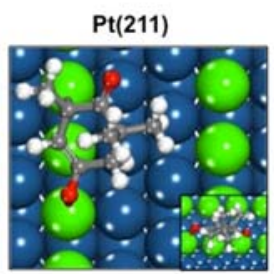

$E_{a d}=0.97 \mathrm{eV}$

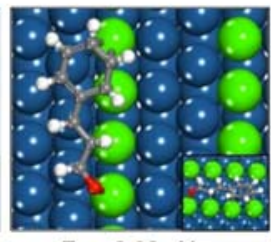

$E_{\mathrm{ad}}=-2.08 \mathrm{eV}$

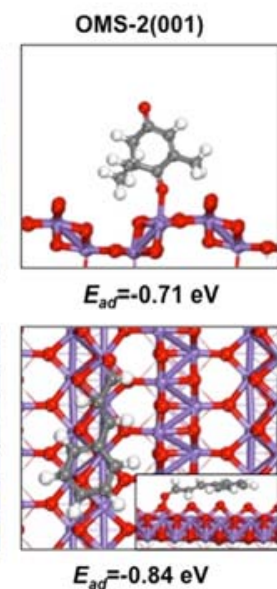

40 Figure 2. Favourable adsorption configurations of KIP (top) and CIN (bottom) on $\mathrm{Pt}(111), \mathrm{Pt}(211)$ and OMS-2(001). The blue, purple, grey, red and white balls denote the platinum, manganese, carbon, oxygen and hydrogen atoms, respectively, and this notation is used throughout the paper. Those $\mathrm{Pt}$ atoms at the edge site of $\mathrm{Pt}(211)$ surface have been

45 highlighted in green. Below each figure panel are the adsorption energies calculated by DFT.

From Figure 2, it can be seen that the adsorption energies on both $\mathrm{Pt}(111)$ and $\mathrm{Pt}(211)$ for KIP are significantly lower than those 50 found for CIN and the adsorption energy for KIP on OMS-2 is comparable with that on the Pt. Figure 3 shows the charge density difference analysis on $\operatorname{Pt}(111)$ for CIN and KIP. The charge density difference $(\Delta \rho)$ is defined as:

\section{$55 \Delta \rho=\rho_{\text {adsorbate/Pt(111) }}-\rho_{\mathrm{Pt}(111)}-\rho_{\text {adsorbate }}$}

where $\rho_{\text {adsorbate/Pt(111) }}$ is the charge density distribution of KIP or CIN adsorbed on $\operatorname{Pt}(111), \rho_{\mathrm{Pt}(111)}$ and $\rho_{\text {adsorbate }}$ are the charge density distributions of isolated $\mathrm{Pt}(111)$ and KIP or CIN, respectively. The

60 structures of the isolated Pt(111) and KIP or CIN are the same as those determined by the optimized structure of KIP or CIN adsorbed on $\mathrm{Pt}(111)$. In each case, charge depletion of the $\mathrm{Pt}$ surface occurs; however, in both the adsorption states for CIN the charge transfer to the molecule is significantly higher than in the

65 case of the KIP. This couples with the higher adsorption energy for CIN vs KIP which leads to a higher surface coverage. This is supported by the excellent correlation between the HERFDXANES shifts observed in Figure 1 and the adsorption energies calculated by DFT shown in Figure 4 on both the $\operatorname{Pt}(111)$ and

$70 \mathrm{Pt}(211)$ surfaces.

From the calculated adsorption geometries, both $\mathrm{C}=\mathrm{O}$ and $\mathrm{C}=\mathrm{C}$ bonds participate in the bonding and, therefore, the molecule adsorption configuration cannot by itself justify the differences in selectivity. The other important parameter is the adsorption energy

75 that is governed by the interaction of the adsorbed molecule with the electronic structure of the active site.

In the case of KIP, the adsorption energy on the OMS-2(001) surface is significantly higher than on $\operatorname{Pt}(111)$ and comparable to the adsorption on $\operatorname{Pt}(211)$. Adsorption is, therefore, favoured on 80 the stepped Pt surface, which is a better representation of the Pt particle. DFT calculations suggest that KIP can adsorb on both $\mathrm{Pt}$ and OMS-2. HERFD-XANES showed a slightly larger shift for Pt- 
$\mathrm{H}_{2}$ than Pt-KIP, indicating that during reaction $\mathrm{H}_{2}$ can compete and possibly displaces KIP from Pt surface. In this case, the reaction is expected to proceed almost exclusively on the support resulting in the high selectivity observed for $\mathrm{C}=\mathrm{C}$ hydrogenation, i.e. the 5 preferred reaction on support in the absence of Pt. Therefore, the presence of $\mathrm{Pt}$ only affects the reaction rate since it activates hydrogen that is then spilled over to the support. In contrast, CIN adsorbs more strongly on both Pt surfaces than on OMS-2(001), especially in the case of $\operatorname{Pt}(211)$. Furthermore the adsorption

10 energy of $\mathrm{CIN}$ on $\operatorname{Pt}(211)$ is 2.14 times higher than that found for KIP. This large change is also reflected in the significant shift in the Fermi energy level measured by HERFD-XANES. In the case of CIN, the adsorption occurs preferentially on Pt and, therefore, the $\mathrm{C}=\mathrm{O}$ is preferentially hydrogenated.
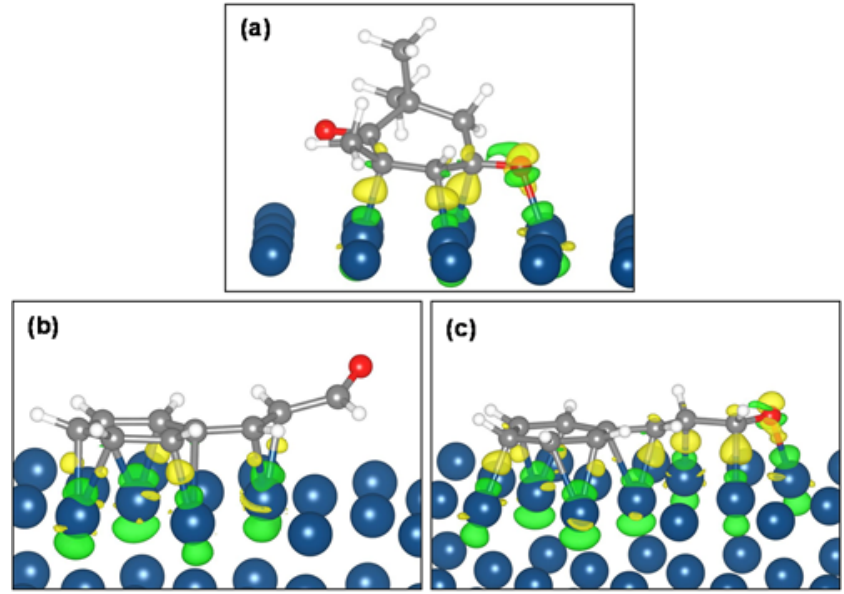

15

Figure 3 Charge density difference analyses on the optimized adsorbed (a) KIP and for (b) the most stable and (c) the next most stable states for CIN on the $\mathrm{Pt}(111)$ surface. The yellow and green contours show the electron charge accumulation and electron charge depletion induced by the surface

20 binding, respectively.

Figure 4. Correlation between the experimentally measure shifts in the HERFD-XANES spectra $\left(E_{\mathrm{f}}\right)$ and the calculated adsorption energies via DFT for the Pt(111) (black) and Pt(211) (red) surfaces.

25 In the present study, we have shown that the combination of state-of-the-art spectroscopy (HERFD-XANES) and theoretical calculations is a powerful and versatile tool to reveal differences in adsorption behaviour for reactants in the liquid phase under reaction conditions. Herein, two hydrogenations with different

30 outcomes have been used to exemplify the technique and

1 B. M. Weckhuysen, In Situ Spectroscopy, American Scientific Publication, 2004

2 J.-D. Grunwaldt, A. Baiker, Phys. Chem. Chem. Phys., 2005, 7, 35263539; J. Sá, C. Kartusch, M. Makosch, C. Paun, J. A. van Bokhoven, E. Kleymenov, J. Szlachetko, M. Nachtegaal, H. G. Manyar, C. Hardacre, Chem. Commun., 2011, 47, 6590-6092; C. Kartusch, M. Makosch, J. Sá, K. Hungerbuehler, J. A. van Bokhoven, Chem CatChem, 2012, 4, 236-242; J. Sá, N. Barrabés, E. Kleymenov, C. Lin, K. Föttinger, O. V. Safonova, J. Szlachetko, J. A. van Bokhoven, M. Nachtegaal., A. Urakawa, G. A. Crespo, G. Rupprechter, Catal. Sci. Technol., 2012, 2, 794-799.

3 M. Makosch, C. Kartusch, J. Sá, R. B. Duarte, J. A. van Bokhoven, K. Kvashnina, P. Glatzel, J. Szlachetko, D. L. A. Fernandes, E Kleymenov, M. Nachtegaal, K. Hungerbühler, Phys. Chem. Chem. Phys., 2012, 14, 2164-2170.

4 E. Kleymenov, J. A. van Bokhoven, C. David, P. Glatzel, M. Janousch, M. Alonso-Mori, M. Studer, M. Willimann, A. Bergamaschi, B. selectivities observed can be broadly understood in terms of the differences in reactant adsorption energies. This strategy can be implemented for the study of other liquid phase catalytic processes if the reactive site particle size is small $(<4 \mathrm{~nm})$ and the surface

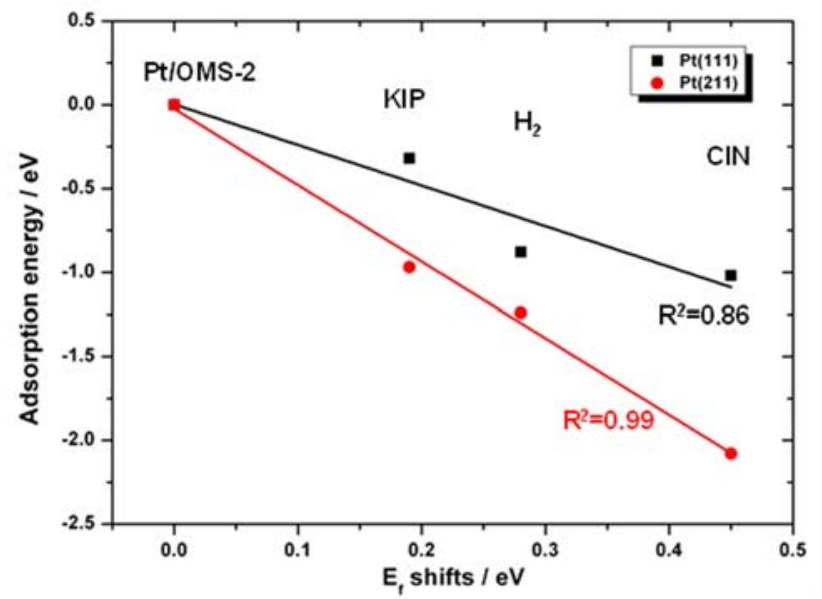

35 coverage is sufficient to be detected spectroscopically ( $c a$. 10$15 \%$ ). In cases where fingerprint spectra can be extracted for each adsorbed molecule, experimental information concerning coverage during reaction and/or competitive adsorption measurements can be performed.

\section{Acknowledgements}

The authors would like to thank Prof. van Bokhoven for the use of the reactor cell. The authors would like to thank the SLS for beam time and the SuperXAS team for their help during beam time. We also thank Queen's University, Belfast for computing 45 time. B.Y. acknowledges the support of Dorothy Hodgkin Postgraduate Award funded by the EPSRC and Johnson Matthey.

\section{Notes and references}

${ }^{a}$ CenTACat, School of Chemistry and Chemical Engineering, Queen's University, Belfast, Northern Ireland, BT9 5AG. Email: Tel.+44 289097

50 4592, c.hardacre@qub.ac.uk

${ }^{b}$ Paul Scherrer Institute (PSI), 5632 Villigen, Switzerland. Tel. +415631 02910,Email: jacinto.sa@psi.ch

'Institute of Physics, Jan Kochanowski University, 25-406 Kielce, Poland $\dagger$ Electronic Supplementary Information (ESI) available: experimental

55 and computational details are provided in the ESI

Henrich, M. Nachtegaal, Rev. Sci. Instrum., 2011, 82, 0651070651013.

5 P. Glatzel, M. Sikora, G. Smolentsev, M. Fernández-García, Catal. Today, 2009, 145, 294-299; F. M. F. de Groot, M. H. Krisch and J. Vogel, Phys. Rev. B, 2002, 66, 195112; P. Glatzel, U. Bergmann, Coord. Chem. Rev., 2005, 249, 65-95.

6 J. A. van Bokhoven, C. Louis, J. T. Miller, M. Tromp, O. V. Safonova and P. Glatzel, Angew. Chem. In. Ed., 2006, 45, 4651-4654; O. V. Safonova, M. Tromp, J. A. van Bokhoven, F. M. F. de Groot, J. Evans and P. Glatzel, J. Phys. Chem. B, 2006, 110, 16162-16164.

7 P. Gallezot, D. Richard, Catal. Rev.-Sci. Eng., 1998, 40, 81-126; U. K. Singh, M. A. Vannice, Appl. Catal. A, 2001, 213, 1-24; B. Yang, D. Wang, X.-Q. Gong, P. Hu, Phys. Chem. Chem. Phys., 2011, 13, 2114621152.

8 H. G. Manyar, B. Yang, H. Daly, H. Moor, S. McMonagle, Y. Tao, G. D. Yadav, A. Goguet, P. Hu, C. Hardacre, ChemCatChem 2013, 5, 506-512. 